\title{
Contribuições da análise crítica do discurso para uma reflexão sobre questões do campo da Educação Ambiental: olhares de educadores em ciências
}

\author{
Isabel Martins ${ }^{1}$, Maíra Jansen Olinisky², Teo Bueno de Abreu³ \\ Laísa Maria Freire dos Santos ${ }^{4}$ - UFRJ
}

resumo: Neste texto, partindo da apresentação das idéias centrais dos estudos críticos do discurso, (i) argumentamos a favor do potencial das perspectivas críticas para a orientação de pesquisas em Educação Ambiental, (ii) problematizamos a natureza dos diferentes discursos que interpelam e que constituem as práticas de educadores ambientais e (iii) debatemos o papel do discurso científico na constituição do discurso sobre meio ambiente nos meios de comunicação. A discussão é feita com base em algumas reflexões sobre as relações entre a pesquisa no campo da Educação Ambiental e a pesquisa no campo da Educação em Ciências, bem como em resultados de investigações, em andamento e concluídas, no Programa de Pósgraduação em Educação em Ciências e Saúde, do Núcleo de Tecnologia Educacional para a Saúde (NUTES) da Universidade Federal do Rio de Janeiro (UFRJ).

palavras-chave: Educação em ciências, Educação ambiental, Análise crítica do discurso, Educação crítica.

abstract: In this paper, having Critical Discourse Studies as a starting point, we: (i) argue for the potential of critical perspectives for research on Environmental Education; (ii) problematize the nature of different discourses which constitute environmental educators' practices and (iii) debate the role of scientific discourse in the constitution of the environmental discourse in the media. The discussion is based upon relationships between research done in the fields of Science Education and Environmental Education, and also on results of investigations carried out at the Science and Health Education Graduate Studies Programme at the Federal University of Rio de Janeiro, Brazil.

keywords: Science education, Environmental education, Critical discourse analysis, Critical perspectives in education.

\footnotetext{
1 Apoio parcial CNPq, e-mail: isabelmartins@ufrj.br

2 Apoio CAPES, e-mail: mjansen7@gmail.com

3 Apoio CNPq, e-mail: teobuenorj@yahoo.com.br

4E-mail: laisa@biologia.ufri.br
} 


\section{As aproximações entre as pesquisas em educação em ciências e em educação ambiental}

Neste trabalho, apresentamos alguns resultados de pesquisas desenvolvidas no Programa de Pós-graduação em Educação em Ciências e Saúde do Núcleo de Tecnologia Educacional para a Saúde da Universidade Federal do Rio de Janeiro que, partindo de uma perspectiva teórica identificada com os estudos críticos do discurso, investigaram questões relacionadas à agenda da Educação Ambiental.

Fortemente influenciados por investigações anteriores no campo da Educação em Ciências e pelo diálogo com a Análise Crítica do Discurso, nossas concepções e problematizações de questões de investigação na área da Educação Ambiental foram mediadas por reflexões acerca da natureza dos saberes que constituem campos que se situam na interface de áreas de conhecimento consolidadas, como a Educação em Ciências e a Educação Ambiental. É interessante notar que esses dois campos de conhecimento possuem histórias e trajetórias distintas, cujas identidades acadêmicas são marcadas por comunidades de prática, eventos e periódicos próprios. A pesquisa em Educação em Ciências consolidou-se, nos últimos anos, como uma área temática em torno da qual se agregam diferentes programas de formação em nível de pós-graduação, cuja produção é difundida por meio de eventos com tradição de décadas e de periódicos com abrangência internacional. Da mesma forma, o crescimento da pesquisa em Educação Ambiental é atestado por meio de indicadores como cursos de pós-graduação, formação de grupos de trabalho na ANPEd, revistas especializadas, entre outros. No entanto, é possível perceber alguns pontos de tangência entre as agendas de pesquisa nos dois campos. Um exemplo é a recorrente discussão acerca das identidades dos campos e de suas relações com outras áreas de conhecimento, que têm estado na pauta das respectivas comunidades (KAWASAKI; MATTOS; MOTOKANE, 2006; DELIZOICOV, 2004). Encontramos nos dois campos reflexões acerca da necessidade de que questões devem ser formuladas, avaliadas, investigadas ou resolvidas a partir de diferentes enfoques científicos, sociais, históricos, culturais e, em alguns casos, utilizando conhecimentos científicos e tecnológicos, ou 
mesmo das comunidades nas quais determinado trabalho é desenvolvido. Carvalho (2006), num comentário a respeito da constituição do campo da Educação Ambiental, chama a atenção para a heterogeneidade de perspectivas que servem de referência para o desenvolvimento do campo:

O fato de as narrativas ou posições que atravessam o campo ambiental serem muito heterogêneas e guardarem um nível significativo de dissenso não contradiz a demarcação de um campo que as engloba. O dissenso faz parte do campo e só pode ocorrer se contar com uma cumplicidade e/ou um consenso básico em torno do que constitui determinado campo (CARVALHO, 2006, p. 41).

Com essa afirmação, podemos entender que, apesar de no campo da Educação Ambiental haver um consenso base sobre determinadas questões, é inerente ao que se construiu nesse campo a existência de diferentes saberes que têm algo em comum, mas que apresentam conceitos, representações e ações diferentes. Sendo assim, a Educação Ambiental, entendida como um campo de conhecimento, agrega várias concepções tanto no campo da pesquisa quanto nas ações de intervenção propriamente ditas.

A heterogeneidade de perspectivas que atravessam o campo também é destacada por pesquisadores do campo da Educação em Ciências. Delizoicov (2004, p. 151) vai além ao identificar essa heterogeneidade com aportes teóricos de diferentes áreas de conhecimento e discutir suas implicações para o estatuto epistemológico da área.

No entanto, na tentativa de melhor caracterizar a área e considerando-a como um campo social de produção de conhecimento e, ainda, que há pesquisas que têm articulação, dentre outros, com referenciais teóricos, modelos e procedimentos da História e da Filosofia (da Ciência); da Psicologia e da Comunicação (BARROS, 2000) consideradas como pertencentes à [sic] Ciências Humanas, parece razoável caracterizar a pesquisa em EC como Ciências Humanas Aplicadas. Esta designação híbrida estaria, então, reforçando a caracterização da área de EC como um campo social de produção de conhecimento autônomo, cuja especificidade, ao mesmo tempo em que contempla aspectos destas 
áreas, se constitui como uma diferenciação a partir delas ao ter como foco de investigação processos educativos, sobretudo os que ocorrem na escola (DELIZOICOV, 2004, p. 151).

Outro paralelo entre os campos da Educação em Ciências e Educação Ambiental diz respeito à necessidade de desenvolver ações visando a preparar as novas gerações para as demandas de uma sociedade científico-tecnológica e para o exercício de cidadania, por meio da tomada de decisão informada, em nível local e global, individual e coletivo, em situações que envolvem questões científicas e suas implicações sociais, tecnológicas e ambientais.

No campo da Educação em Ciências essa idéia tem sido problematizada por pesquisadores que discutem o conceito de alfabetização científica (ROBERTS, 2007). Podemos nos perguntar, por exemplo: o que significa ser alfabetizado: possuir conhecimentos sobre os produtos e processos da ciência ou tomar parte em situações sociais nas quais o conhecimento científico está envolvido? Essas possibilidades seriam mutuamente exclusivas? Como se estruturam esferas discursivas das quais participam sujeitos sociais que dominam saberes de diferentes naturezas (acadêmica, prática, jurídica etc.)? Como integrar essas diferentes demandas com as necessidades, interesses e expectativas dos cidadãos na definição de uma agenda para as ações e investigações sobre alfabetização científica? Quais outros parâmetros deveriam balizar as ações nesse campo?

Transpondo essas questões para o contexto de uma educação voltada para a solução de problemas concretos relacionados ao meio ambiente, consideramos que, além de desenvolver técnicas e conhecimentos, esta pressupõe o estabelecimento de uma prática comunitária capaz de abordar problemas comuns à coletividade, como a falta de saneamento ou a expansão desordenada das cidades. Entretanto, freqüentemente se observa que o poder de decidir e o de intervir para transformar o ambiente estão distribuídos social e geograficamente de modo desigual em nosso mundo. Quem detém o poder econômico e político tem a maior capacidade de intervenção no meio ambiente, seja de forma direta, por deter maior potencial tecnológico, seja de forma indireta, 
por gerar miséria, através da concentração de renda, que também acarreta impactos ambientais adversos. Mas isso nem sempre é evidente.

Dessa forma, vemos, para ambos os campos, a relevância de uma agenda de desafios relacionados a necessidades impostas por problemas eminentemente aplicados, cuja solução envolve ações e tomadas de decisão, bem como o estabelecimento de relações entre dimensões sociais, tecnológicas e científicas associadas a questões do cotidiano.

Ao discutirem sobre como os campos da Educação em Ciências e da Educação Ambiental se organizam a partir de perspectivas relacionadas à educação crítica, Vasconcellos et al. (2007) consideram que esses têm respondido de forma diferente a tais desafios. Apesar de reconhecerem que enfoques como "Entendimento Público da Ciência (EPC)", "Ciência, Tecnologia e Sociedade (CTS)" e "Alfabetização Científica e Tecnológica (ACT)" promovem uma abordagem crítica acerca das questões sociais, os autores consideram que, de um modo geral,

o campo da educação ambiental se ocupou mais do aprofundamento da dimensão política da Educação, enquanto o campo da educação em ciência, no enfoque da linha de pesquisa analisada no ítem [sic] anterior, dedicou-se mais a pesquisar sobre metodologias de ensino, envolvendo-se profundamente com o construtivismo na sua vertente mais cognitivista. (VASCONCELLOS et al., 2007).

Com base nessa constatação, os autores sugerem que uma aproximação entre os dois campos pode resultar na desejável articulação de dimensões políticas e pedagógicas. Eles vão além e apostam no potencial das abordagens críticas para a educação (GIROUX, 1986) e na categoria freireana do diálogo (FREIRE, 1987) como instância promotora dessa aproximação. Aproximações entre os campos também são propostas por Carvalho (2007), que discute as bases de um ideário comum que orienta práticas político-ideológicas, bem como acadêmico-científicas e pedagógicas, nos campos da educação ambiental e do ensino de ciências da natureza.

Gough (2002), por sua vez, sugere que a educação em ciências deve estimular o que ela denomina de um "pensar ecológico". Para essa autora australiana, resistências à inclusão da educação ambiental nos currículos fazem com que a educação em ciências desempenhe um papel de 
'hospedeiro' da educação ambiental nos espaços escolares. Apostando nas metáforas de conteúdo biológico, Gough considera que para trabalhar a educação ambiental de forma adequada seria necessário repensar essa função da educação em ciências em termos de uma relação de 'mutualismo' entre esta e a educação ambiental. Dentro dessa perspectiva, seriam permitidos novos olhares, trocas e deslocamentos que levariam a mudanças na pauta desses dois campos no sentido de, por um lado, reconstruir a educação em ciências em função dos objetivos de uma alfabetização científica e de críticas propostas pelas abordagens pós-colonialistas e feministas e, por outro, movimentar a educação ambiental para além da visão estática da Conferência de Tblisi na direção das propostas da Agenda 21.

Finalmente, o diálogo entre esses campos é também facilitado pela circulação de artigos de pesquisa em Educação Ambiental em periódicos e eventos de pesquisa de Educação em Ciências, o que dá visibilidade e promove potenciais reflexões sobre as relações entre os campos. Num levantamento referente ao período de 1999 a 2006, Santos e Martins (2007) identificaram, em periódicos do campo da Educação em Ciências, artigos que discutiam as seguintes temáticas no contexto da Educação Ambiental: ensino/aprendizagem, concepções de alunos e/ou professores, representações sociais, avaliação e formação de educadores. Além desses, foram encontrados trabalhos que apresentavam o estado da arte das publicações de teses e dissertações em Educação Ambiental. Sua análise demonstra, ainda, paralelos nos encaminhamentos metodológicos dos trabalhos dos dois campos, que favorecem desenhos de pesquisas de cunho qualitativo, utilizam instrumentos tais como questionários e entrevistas para coleta de material empírico e, freqüentemente, empregam procedimentos de análise de conteúdo para tratamento dos dados.

\section{Educação, discurso e mudança social: a contribuição das teorias críticas}

Em nossas investigações, temos discutido, entre outros aspectos constitutivos dos saberes em Educação em Ciências, sua natureza interdisciplinar e sua identidade construída na interface de diversos campos de conhecimento. Um diálogo particularmente frutífero tem sido aquele 
com os estudos de discurso. Mais particularmente, com base nas vertentes críticas da Análise do Discurso, temos investigado temas relacionados às linguagens e mediações presentes em materiais e práticas educativas (MARTINS, 2007). Uma primeira contribuição das teorias críticas da linguagem é permitir o questionamento da exagerada importância dada à apreensão de informações ou de vocabulário técnico no alcance da alfabetização científica. Ao considerar a linguagem da ciência como ação social e como o resultado de uma reconstrução semiótica da experiência humana, algumas de suas características, tais como a alta densidade léxica, as descontinuidades semânticas e o uso de termos técnicos, adquirem um novo sentido na medida em que refletem aspectos da natureza do conhecimento científico e dos processos sociais de sua construção. Outra contribuição importante é a nova forma pela qual podemos pensar textos relacionados ao discurso científico, tais como currículos de ciências, resultados de estudos de avaliação, exibições em museus, livros didáticos ou textos de divulgação científica. Esses deixam de ser apenas recomendações a serem seguidas ou conteúdos a serem aprendidos e transformam-se em materializações de discursos sobre ciência na sociedade. Nesse sentido, podemos nos perguntar acerca da pluralidade de perspectivas possíveis para pensar a alfabetização científica. Finalmente, compreender os textos a partir de suas condições sociais de produção não significa necessariamente ficar aprisionado no pessimismo das abordagens deterministas. A Análise Crítica do Discurso está interessada em compreender tanto efeitos sociais nos textos como efeitos sociais dos textos (FAIRCLOUGH, 2004), chamando atenção para o fato de que as pessoas respondem aos textos de forma ativa, interessada e transformadora. Dessa forma, o foco da discussão muda para as possibilidades de construção de sentidos e de ação social e permite pensar em quais são os contextos que garantem efetiva participação na sociedade.

A aproximação de perspectivas críticas nos permitiu confrontar uma justificativa naturalizada na comunidade de educadores em ciências, qual seja, a de que as ações de alfabetização científica são suficientes para a tomada de decisão informada e para o exercício de uma cidadania responsável. O argumento pode ser desdobrado no contexto de outras questões atuais, como, por exemplo, a educação nutricional, as campanhas 
para prevenção da gestação precoce, o aquecimento global, o uso racional de recursos hídricos. Num cenário onde um modelo de desenvolvimento científico levou a um modelo de desenvolvimento econômico essencialmente predatório dos recursos naturais, encontramos aí mais um ponto de convergência do debate entre os campos da Educação em Ciências e da Educação Ambiental.

Segundo Martins (2007), as abordagens que vão além da discussão acerca do que o cidadão precisa saber sobre ciência o fazem dentro de uma perspectiva funcionalista, na qual o indivíduo formado seria capaz de contribuir para o progresso da sociedade e não de questionar suas bases, problematizar suas contradições, refletir sobre seu papel social e vislumbrar possibilidades de transformá-la.

Além disso, numa perspectiva crítica, é essencial a aproximação entre educador e educando. O educador não é visto apenas como detentor do conhecimento, mas também como mediador dos saberes e fazeres (técnico-científicos e populares), estabelecendo com o educando a cumplicidade, a confiança, o respeito mútuo, a lealdade e a cooperação e propiciando uma troca de conhecimentos. É possível ao educador, apesar da assimetria de papéis entre educando e educador, viabilizar o estabelecimento de um espaço educativo participativo e dialógico, em que o educando, sujeito do processo educativo, sinta-se integrado na construção e reconstrução do processo de aprendizagem. Para isso, a conduta do educador deve ser, essencialmente, de mediação, de informação e de interação afetiva. O educador deve criar mecanismos de organização do processo de aprendizagem com atividades que permitam trocas de experiências, que valorizem a participação do educando e que busquem coerência entre valores, discurso e prática.

\section{Exemplos de investigações sobre temas relacionados à Educação Ambiental desenvolvidos a partir de perspectivas críticas}

\section{A Análise Crítica do Discurso}

Relatamos aqui os principais resultados de duas investigações que têm em comum sua base teórico-metodológica: os estudos críticos do 
discurso. Concebendo o discurso como um modo de ação historicamente situado, essa perspectiva tem origem nas proposições seminais de Mikhail Bakhtin sobre o caráter dialógico da linguagem e seu papel constitutivo de identidades e práticas sociais. Os lingüistas críticos, tais como Robert Hodge, Gunther Kress, James Gee e Norman Fairclough, avançam na caracterização de uma relação dialética entre discurso e sociedade. Com base em Fairclough (2001), consideramos que o discurso se define a partir de relações entre três dimensões principais: (i) textos; (ii) práticas discursivas, isto é, os contextos de produção, circulação e recepção desses textos; e (iii) práticas sociais nas quais esses processos se inscrevem. É exatamente o caráter mutuamente constitutivo dessas três dimensões que torna a análise de discurso pertinente para a investigação de eventos e práticas sociais e que justifica tomar a linguagem como objeto de estudo para compreender aspectos das práticas sociais de divulgar ou ensinar ciências na escola. De forma análoga, essa relação constitutiva entre as dimensões semiótica e social permite discutir em que medida mudanças discursivas correspondem, influenciam, promovem ou impedem mudanças nas práticas sociais. Enfatizamos essa possível relação porque nosso próprio trabalho como investigadores não é livre de intenções, compromissos e posicionamentos ideológicos e sociais. Em nosso caso, as mudanças que desejaríamos ver efetivadas dizem respeito ao estranhamento de posicionamentos e visões de mundo por nós naturalizados, à conscientização do caráter heterogêneo do nosso discurso e a uma maior aproximação e reconhecimento recíproco das contribuições, olhares e propostas de diferentes atores sociais comprometidos com a Educação Ambiental.

$\mathrm{Na}$ Análise Crítica do Discurso, o caráter heterogêneo do discurso é discutido por meio de categorias analíticas, como a intertextualidade e a interdiscursividade. A intertextualidade, conceito elaborado por Kristeva no final dos anos 1960, a partir de trabalhos de Bakhtin, pode ser entendida como a propriedade que os textos têm de conter fragmentos de outros textos que podem ser distinguidos explicitamente ou mesclados e que o texto pode assimilar, contradizer ou ecoar. Em outras palavras, quando falamos ou escrevemos algo, o fazemos recorrendo implicitamente ou explicitamente a outros textos, outras conversações, estabelecendo, portanto, relações entre textos. Quando manifestadas explicitamente, identifica-se a intertextualidade manifesta, cuja realização textual se dá por meio de representação do discurso, 
pressuposição, negação, metadiscurso e ironia. Quando são identificados elementos de determinadas configurações discursivas, por exemplo, um gênero textual, e não referências a outros textos, diz-se que a intertextualidade é constitutiva, enfatizando que o foco está nas relações entre o texto e convenções discursivas e não entre o texto e outros textos.

Fairclough (2001) parte das contribuições de Foucault para a análise social do discurso articuladas aos conceitos de hegemonia de Gramsci, de ideologia de Althusser, de intertextualidade de Kristeva, e às abordagens da Lingüística Sistêmica Funcional de Halliday, para elaborar sua proposta metodológica de análise crítica do discurso, textualmente orientada. Apesar de reconhecer a importância de Foucault na análise social do discurso, Fairclough rompe com algumas de suas idéias para desenvolver sua proposta, principalmente no que diz respeito ao espaço dedicado às possibilidades de mudança discursiva e, conseqüentemente, de mudança social, que estão no centro de suas inquietações. Foucault se preocupa em sua obra em mostrar um modo de investigar não o que está por trás do que foi dito, mas sim as condições de existência de um determinado discurso (FISCHER, 2001). Entre as principais contribuições das idéias de Foucault destacadas por Fairclough estão: a natureza constitutiva do discurso e a natureza discursiva e política do poder. Na contribuição foucaultiana sobre a natureza constitutiva do discurso, Fairclough ressalta a constituição discursiva da sociedade, (re)produzindo-a e transformando-a em vários níveis, dos objetos de conhecimento, das estruturas conceituais, bem como dos sujeitos sociais e suas relações. Nessa visão, o discurso estabelece uma relação ativa com a realidade: além de representá-la, constrói significados para ela. Nesse sentido, Foucault formula o conceito das formações discursivas como sistemas de dispersão, entre os quais podemos definir uma regularidade no que se refere aos objetos, estilo, conceitos. Essas regularidades são chamadas regras de formação e definem as condições de existência, coexistência, manutenção, modificação e desaparecimento do conjunto de enunciados que pertencem a uma mesma formação. Essas regras são constituídas por elementos discursivos anteriores e a articulação desses elementos faz do discurso uma prática social - prática discursiva para Foucault (FAIRCLOUGH, 2001). Foucault, de acordo com Fairclough (2001), sugere ainda que uma formação discursiva constitui seus objetos, 
estruturas conceituais e posições de sujeito de uma forma restrita, na qual as limitações de uma formação são função das relações entre as práticas discursivas que compõem tal formação, assim como das relações interdiscursivas envolvendo as formações. Tais relações interdiscursivas, articulações entre diferentes formações, determinam também as delimitações de cada formação e são chamadas por Fairclough, usando um termo foucaultiano, ordens de discurso. Os objetos são as entidades reconhecidas dentro de cada formação discursiva que são tomadas como alvos de investigação e ação.

No que se refere à constituição dos sujeitos sociais, Foucault, de acordo com Fairclough (2001), comenta que o sujeito é constituído, reproduzido e transformado na prática social e por meio dela. A identidade social do sujeito afetará a forma como ele usa a linguagem, bem como o uso de linguagem afetará ou moldará sua identidade social. Estamos tratando na realidade de uma relação dialética entre discurso e subjetividade, a qual considera os sujeitos sociais como simultaneamente moldados pelas práticas discursivas e capazes de remodelar e reestruturar essas práticas.

$\mathrm{Na}$ próxima seção, discutimos como esse quadro teórico de referência tem permitido explorar questões acerca da constituição do campo da Educação Ambiental, da relação entre os diferentes discursos que constituem o discurso ambiental, além de explorar o impacto dessa discussão para a formação de educadores ambientais. Sendo assim, a proposta analítica das duas investigações a seguir considera a linguagem em uso, ou seja, os processos de construção de sentidos e de seus efeitos, as formas de diálogo entre sujeitos sociais, históricos, discursivos e as formas de dizer e de ser no mundo.

\section{Construindo uma identidade de educador ambiental}

A primeira investigação aqui relatada examinou a produção de sentidos para a Educação Ambiental a partir da análise de falas de licenciandos em Ciências Biológicas (OLINISKY, 2006). Os dados foram recolhidos por meio de aproximadamente 60 horas de videogravação de interações discursivas, realizadas no âmbito da disciplina de 
Instrumentação para o Ensino de Ecologia, do Curso de Bacharelado em Ciências Biológicas ${ }^{5}$, oferecida pelo Departamento de Ecologia da UFRJ. As análises buscam estabelecer relações entre as três dimensões do discurso, ou seja, as práticas sociais relacionadas à Ecologia, as práticas discursivas instituídas pela disciplina e, finalmente, os textos dos enunciados dos professores e dos licenciandos. Discutimos aqui três aspectos constitutivos dos discursos analisados, a saber: a tensão entre diferentes formações discursivas relacionadas às questões ambientais, a identidade da EA como um campo de conhecimento e ação e a construção da identidade de educadores ambientais.

Seguindo as idéias de Foucault, apropriadas por Fairclough, caracterizamos o campo emergente da Educação Ambiental como constituído por duas formações discursivas: a formação ecologista e a formação conservacionista. Apesar de apresentarem pontos de continuidade e muitas vezes parecerem extremos de um continuum de concepções, consideramos que ambas se referem a objetos e conceitos diferentes, assim como a diferentes estilos das enunciações, que, por vezes, se relacionam de maneira controversa às posições ocupadas pelos sujeitos dos enunciados.

Quanto aos seus objetos, a formação ecologista diz respeito principalmente à mudança paradigmática, de construção e legitimação do conhecimento, e social, bem como aos mecanismos que podem tornar essas mudanças possíveis, ao passo que a preservação/conservação do meio ambiente natural apenas tangencia suas preocupações principais. A formação conservacionista, por sua vez, inverte essa ordem, referindo-se principalmente às necessidades e às possibilidades de conservação/ preservação do meio ambiente natural, tratando as questões relativas às mudanças social e paradigmática como adjacentes. Nesse mesmo sentido, os conceitos que se constituem como aparato de conhecimento para ambas também são muito

5 Formalmente registrada como disciplina do Bacharelado em Ecologia, esta disciplina, tradicionalmente ministrada por professores do Departamento de Ecologia que possuem envolvimento com a temática da Educação Ambiental, é sempre muito procurada pelos alunos da Licenciatura em Ciências Biológicas. No semestre em que foram coletados os dados da pesquisa aqui relatada, todos os estudantes matriculados eram alunos de Licenciatura, que cursaram a disciplina como eletiva. 
diversos. Para a formação conservacionista, os conceitos básicos para as ações educativas são conceitos ecológicos de compreensão do funcionamento do ambiente natural independentemente da ação humana. Para os sujeitos dessa formação discursiva, as discussões do campo da Educação, assim como seus conceitos e principais categorias teóricas, são também secundárias (LOUREIRO, 2004). Para os ecologistas, os conceitos que sustentam seu discurso vêm principalmente do campo científico da Educação, mas com forte caráter de militância e ação política, de onde buscam suas principais referências do estilo lingüístico de seus enunciados. $\mathrm{Na}$ formação conservacionista, o estilo lingüístico predominante é, sem duvida, o científico-acadêmico, principalmente relacionado às ciências naturais.

Entretanto, apesar de defendermos essas duas tendências como formações discursivas diferentes, compreendemos, como dito anteriormente, que apresentam regiões de contato, algumas vezes harmoniosas, como em propostas que tentam ser agregadoras, e outras vezes de forte tensão e lutas ideológicas e de poder. Por essas razões, defendemos que as relações interdiscursivas do ecologismo com o conservacionismo estabelecem, também, os limites entre si e se constituem como ordens de discurso, na medida em que Fairclough (2001) as coloca como uma posição frutífera para a orientação histórica da mudança discursiva: pensar o interdiscurso (ordem de discurso) como uma configuração complexa e interdependente de formações discursivas.

Podemos dizer que a tensão entre essas duas formações discursivas se refletiu nas discussões da disciplina. Essa tensão ficou especialmente clara na primeira aula registrada, que se tornou um espaço de discussão sobre concepções e perspectivas de Educação Ambiental devido à dúvida surgida com respeito à relação entre Ecologia e Educação Ambiental. A expectativa do grupo ao optar pela inscrição na disciplina de Instrumentação para o Ensino de Ecologia estava relacionada à possibilidade de desenvolver uma ação de Educação Ambiental, mas duas licenciandas, que possuíam leituras e experiências anteriores no campo da Educação Ambiental, estranharam a ênfase dada aos conhecimentos ecológicos logo no início. Nesse contexto, propuseram discutir a relação entre a Ecologia e a Educação Ambiental e a aula toda foi destinada a esse fim. Com o desenrolar da disciplina, essa tensão tornou-se menos 
acentuada e a visão conservacionista esteve mais presente nas discussões do grupo. Este deixou então de priorizar o espaço para os questionamentos em função das limitações de tempo impostas pelo cronograma de planejamento e execução do trabalho de fim de curso, isto é, a elaboração e realização de um curso para professores de ciências de uma cidade no Norte Fluminense.

Um segundo aspecto importante diz respeito ao reconhecimento da Educação Ambiental como um campo de conhecimento no desenvolvimento da disciplina. Tal reconhecimento foi expresso em termos de referências esparsas a alguns espaços de produção discursiva da área. Por exemplo, apenas na primeira aula houve referência a um espaço específico do campo da Educação Ambiental - o II World Environmental Education Congress, realizado no Rio de Janeiro em 2004 e do qual participaram algumas das alunas da turma. No tocante aos textos que circularam entre os licenciandos e que subsidiaram as discussões em aula e o desenvolvimento de propostas para o curso, vimos que predominaram aqueles que inventariavam e descreviam atividades lúdicas para a Educação Ambiental, sendo que muitas delas sequer destacavam uma dimensão pedagógica, consistindo apenas na sugestão e descrição de brincadeiras e atividades que pudessem ser realizadas ao ar livre. Os textos científicos, especialmente legitimados no ambiente acadêmico de uma disciplina universitária, eram todos relativos à Ecologia. Não incluíram, em nenhum momento, textos científicos ou acadêmicos do campo da Educação, da Educação em Ciências ou da Educação Ambiental, embora questões de natureza didáticopedagógica, como as relativas ao público-alvo ou aos objetivos pedagógicos, entre outras, estivessem sempre presentes durante a elaboração das atividades do curso a ser elaborado. Em outras palavras, as bases da discussão sobre Educação Ambiental foram relacionadas a um conjunto heterogêneo de referências que incluíam dados da experiência, informações da mídia etc. e que não tinham aderência à produção do campo de conhecimento da Educação Ambiental. Além disso, e a despeito da valorização do tema explicitada pelos professores da disciplina em certos momentos, o espaço destinado para discutir as questões relativas a(o campo da) Educação Ambiental especificamente foi, em geral, incidental, ao contrário do espaço para o estudo da Ecologia, amplo e muito valorizado. 
Relações entre esses dois elementos discutidos nos parágrafos anteriores, isto é, a tensão entre ecologismo e conservacionismo e a constituição da identidade do campo da Educação Ambiental, puderam ser identificadas nos discursos de alguns dos licenciandos. Se por um lado percebemos o predomínio do conservacionismo na disciplina em geral, de outro podemos ver também que as idéias ecologistas começam a achar o seu espaço nesse ambiente. Logo na primeira aula, observamos que os licenciandos que não possuíam vivências ou experiências em outros contextos de Educação Ambiental apresentavam idéias conservacionistas em relação à Educação Ambiental de forma muito naturalizada. As relações entre Ecologia e Educação Ambiental eram muito claras, não se constituíam num problema e não questionavam ou se contrapunham às orientações para o desenvolvimento do curso. Nesse contexto, sempre que foi colocada uma interpelação contraditória (FAIRCLOUGH, 2001), ela causava um desequilíbrio, caracterizado como "entropia" pelo próprio grupo de alunos. Tais desvios ou quebras da ordem se constituíam em desequilíbrios das certezas anteriores e geravam novas questões e espaços para discussão por parte de todo o grupo.

As participações de algumas licenciandas mais diretamente envolvidas com práticas de Educação Ambiental foram determinantes para essa dinâmica e proporcionaram discussões altamente relevantes acerca da natureza do campo, do seu estatuto, das suas práticas constitutivas e das suas relações com outros campos. Essa relevância é particularmente clara no que diz respeito às demandas da prática discursiva da formação inicial de professores de ciências, que são muitas vezes os responsáveis pelas ações de Educação Ambiental nas escolas. Nesse sentido, as pressões pela consideração da Educação Ambiental como um campo de conhecimento que possui uma identidade própria, mesmo que incipientes e restritas a um subgrupo dos licenciandos, devem ser valorizadas. Todos os que participaram dessas discussões puderam ir ao encontro de tais idéias, o que será extremamente valoroso, dado o espectro de atuação em suas futuras ações profissionais enquanto autores, reprodutores ou multiplicadores de práticas que não são neutras e que possuem maior ou menor grau de filiação ou afinidade a uma determinada formação discursiva. 
Essa discussão nos remete a um terceiro aspecto, que diz respeito à construção identitária dos professores de ciências como educadores ambientais. Recordamos aqui como, na primeira aula, o graduando João lembra ao grupo que eles são futuros professores de ciências e biologia, áreas do saber que têm suas especificidades e a partir das quais se constituem suas contribuições para a Educação Ambiental. Essa fala de João suscita um questionamento sobre questões relacionadas à inter, multi e transdisciplinaridade no contexto da Educação Ambiental, bem como à necessidade de concebê-la no contexto das suas relações com diferentes campos de conhecimento, o que não é tarefa trivial especialmente num universo disciplinar como é o nosso sistema formal de ensino. Nesse sentido, as contribuições da Educação Ambiental para as ciências naturais, como a biologia, são muito debatidas nas publicações do campo, principalmente no que diz respeito à mudança paradigmática de construção e legitimação do conhecimento. No entanto, as contribuições da Educação em Ciências para a Educação Ambiental não têm tanto espaço de discussão, nem mesmo em publicações específicas da área de Educação em Ciências. Tendo isso em vista, cabe questionar qual a contribuição do professor de ciências e biologia para o campo da Educação Ambiental. Sendo assim, reconsideramos o estranhamento em relação à grande valorização do conservacionismo nessa prática discursiva. Trata-se de um ponto de vista que vai ao encontro das ciências naturais, uma formação discursiva que é parte desse referencial e que como tal deve ser também valorizada. O que não se pode esquecer é que essas idéias fazem parte de um campo maior e devem ser articuladas como as demais idéias deste campo, de forma a possibilitar a constituição e o reconhecimento de sua identidade.

Entretanto, se em termos de conteúdo as discussões específicas do campo da Educação Ambiental não tiveram muito espaço, em termos de prática educativa, a proposta dessa disciplina se mostrou bastante inovadora e de acordo com as idéias também inovadoras da Educação Ambiental. A dinâmica das aulas incluiu discussões nas quais todos tiveram voz. A estrutura circular de organização dos participantes permitiu que não houvesse, no espaço físico, um lugar privilegiado para os professores responsáveis, e todos pudessem se olhar da mesma forma. Além de não se destacarem no espaço físico ocupado, os professores também interferiam 
pouco na dinâmica da discussão, deixando para os alunos a possibilidade e responsabilidade de elaborar coletivamente um curso. A participação dos licenciandos foi muito valorizada - o que foi percebido pelos mesmos - e suas idéias se desenvolveram com um grau de liberdade acima do disponível em dinâmicas mais tradicionais de sala de aula. $O$ trabalho coletivo e a articulação das idéias e anseios individuais foram elementos centrais dessa dinâmica.

A questão é por que, apesar desse clima de abertura e acolhimento de novas idéias, a participação não se constituiu na adesão e reafirmação de visões mais abrangentes ou mais problematizadoras da Educação Ambiental? Provavelmente, a resposta pode estar relacionada aos compromissos e à natureza do próprio ambiente social onde as interações se deram: os compromissos com os produtos, prazos, com os referenciais de conhecimento, entre outros. Supomos também que a complexidade de relações envolvidas na caracterização do campo da Educação Ambiental demanda significativo tempo de reflexão e amadurecimento das idéias. Em outras palavras, a vivência dessa dinâmica de aula certamente influencia a forma como a Educação Ambiental é compreendida, o que nos remete novamente à questão da construção da identidade de educadores(as) ambientais.

É provável que a intensidade de identificação de cada um desses licenciandos como educadores ambientais seja bem diferente porque, apesar de terem passado por oportunidades de construção semelhantes ao longo da disciplina, o ponto de partida de cada um deles foi muito diverso. De forma geral, podemos dizer que os alunos que cursam essa disciplina já se identificam previamente com a Educação Ambiental em alguma medida. Em primeiro lugar, por se tratar de uma disciplina de caráter eletivo, não há obrigatoriedade em cursá-la. Em segundo, porque, apesar de não levar a Educação Ambiental em seu nome, esta aparece claramente na ementa e são feitas menções diretas à mesma no desenrolar das atividades. Essas são também as idéias que circulam entre os alunos nos espaços comuns que freqüentam na universidade. A essa identificação prévia podem ser somadas também as identificações mais individuais, como nos casos daqueles que já circulavam em espaços do campo em questão e de alguns que já, inclusive, desenvolviam ações educativas com esse propósito. Durante o período de desenvolvimento da disciplina, apesar das 
oportunidades semelhantes, podemos atentar ao fato de que os licenciandos com menor aporte prévio do campo da Educação Ambiental provavelmente tiveram mais acesso a novidades do que os outros. Enquanto estes muitas vezes se encarregaram de trazer novidades para o debate, aqueles tiveram, provavelmente, a primeira oportunidade de contato com elas, que podem se sedimentar e constituir suas novas identidades de educadores(as) ambientais.

Ademais, não podemos negar que, de alguma forma, a visão conservacionista interpela todos esses alunos, principalmente devido à sua formação básica em biologia. Durante o curso, existe uma valorização da maneira "biológica" de ver o mundo, praticamente independente da ação humana. Essa, como um dos elementos constitutivos do conservacionismo, possibilita essa identificação, que pôde ser percebida pela facilidade com a qual as idéias conservacionistas predominaram ao longo do período da disciplina analisada. Entretanto, foi por meio das licenciandas que apresentaram um histórico de envolvimento com o campo que as lutas epistemológicas entre as formações discursivas da Educação Ambiental e do educador ambiental mostraram-se distintas - ou complementares - daquelas do professor de ciências e biologia. As aulas foram, assim, um espaço para que essa questão viesse à tona, e ela de fato permaneceu pontualmente ao longo do período. A consideração dessa especificidade é importante na medida em que a falta de reconhecimento do campo da Educação Ambiental pode levar à formação de potenciais educadores ambientais que não são capazes de reconhecer o campo em que atuam nem de atentar para as formas pelas quais podem contribuir para ele.

Como argumentado neste trabalho, os textos são elaborados pelos sujeitos, mas também moldam os sujeitos, ou seja, estão envolvidos em processos de atribuir significados e têm efeitos causais. É mais comum encontrarmos uma discussão sobre os efeitos sociais nos textos, mas o referencial adotado também considera a relação dos efeitos sociais dos textos. Isso quer dizer que os textos podem trazer mudanças ao conhecimento, crenças, atitudes, valores, experiências e também ter uma série de efeitos políticos e sociais. Nesse sentido, podemos considerar a reelaboração da proposta curricular da disciplina Instrumentação para o Ensino de Ecologia como uma mudança no plano das práticas sociais no 
Departamento de Ecologia da Universidade, produzida a partir tanto da interação dos docentes responsáveis pela disciplina quanto do texto que relatou a investigação em questão.

Em pesquisas futuras, pode ser interessante verificar como o campo da Educação Ambiental, bem como suas lutas e contradições, interpelam os professores de Ciências Biológicas em formação inicial em outros contextos universitários. Dessa forma, poderemos, dialeticamente, ter idéia de como o campo está se constituindo em relação à educação formal e sobre quem são os professores(as) de ciências e biologia/ educadores(as) ambientais que estão se inserindo nas escolas. Da mesma forma, seria muito enriquecedor que houvesse outros estudos que tivessem como sujeitos licenciandos de outros cursos, afinal, não são só os(as) professores(as) de ciências e biologia que constituem a vertente do ensino formal do campo da Educação Ambiental.

Outro rumo de pesquisa que este trabalho abre é o de relacionar a perspectiva da análise crítica do discurso - textualmente orientada - para a mudança discursiva, em outras práticas discursivas, como forma de contribuição para a compreensão das dificuldades e possibilidades envolvidas na constituição do campo da Educação Ambiental para que possa ser reconhecido como tal.

\section{Discursos sobre meio ambiente na mídia}

A segunda investigação aqui relatada diz respeito à constituição dos discursos sobre meio ambiente construídos na mídia e ocorreu por meio da análise de um suplemento mensal do Jornal do Brasil, intitulado JB Ecológico. Nas suas reportagens, entrevistas, propagandas etc., encontramos discursos sobre meio ambiente e ecologia caracterizados por uma heterogeneidade típica dos discursos que se situam nas interfaces dos vários outros discursos relacionados a saberes, áreas de conhecimento e de atuação da sociedade civil organizada, política e economicamente (LEFF, 2002), entre eles os discursos oriundos das ciências ambientais, jurídicas, econômicas, entre outros, além daqueles advindos da mídia, das áreas da saúde, das políticas públicas e das diferentes esferas de saber cotidiano. 
Figura 1: Heterogeneidade do discurso sobre meio ambiente.

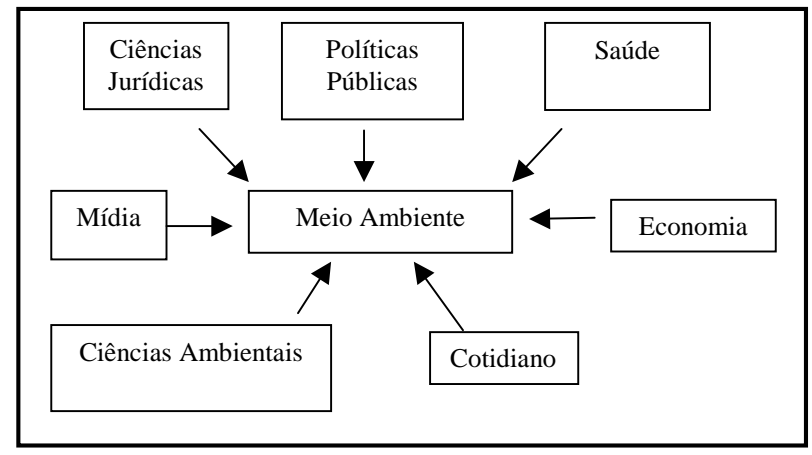

A figura 1 dá uma visão simplificada e resumida dos elementos discursivos que ajudam a compor o discurso sobre o meio ambiente. É importante ressaltar que, no interior de cada um desses discursos, existem antagonismos que resultam na dificuldade de se obter uma única definição para cada um deles e, conseqüentemente, de demarcar suas fronteiras. Nesse contexto, o estudo do Suplemento JB Ecológico se apresenta como uma oportunidade de investigação de uma forma de articulação desses discursos sob um ponto de vista de sua inserção em um diálogo com o grande público leitor do Jornal do Brasil.

Nosso interesse principal residia na identificação das formas pelas quais o discurso científico toma parte nessa articulação dentro de um veiculo de comunicação. Apresentamos aqui um recorte dessa análise, que se refere aos editoriais das doze primeiras edições publicadas entre março de 2002 e janeiro de 2003 (ABREU, 2007), destacando aspectos da posição enunciativa de seu autor e sua aderência a diferentes discursos sobre meio ambiente que circulam na sociedade.

Nesse trabalho, os conceitos de intertextualidade e interdiscursividade foram utilizados para compreender as diferentes interfaces que o discurso ambiental possui com outros discursos contemporâneos. Para Fairclough (2001), a intertextualidade manifesta é o caso em que textos específicos são explicitamente referenciados, enquanto a interdiscursividade corresponde aos casos nos quais um tipo de discurso é constituído por meio da combinação de elementos de diferentes ordens 
de discurso. Nessa investigação, estes conceitos foram operacionalizados em termos de algumas de suas subcategorias, como mostra o quadro 1.

Quadro 1: Categorias analíticas usadas na análise

\begin{tabular}{|l|l|l|}
\hline \multirow{2}{*}{ Intertextualidade } & $\begin{array}{l}\text { Representações } \\
\text { discursivas }\end{array}$ & diretas (citações) \\
\cline { 3 - 3 } Interdiscursividade & \multirow{2}{*}{ Gênero } & $\begin{array}{l}\text { Padrões textuais estáveis, típicos de diferentes } \\
\text { campos da atividade humana (artigos científicos, } \\
\text { conversas informais etc.) }\end{array}$ \\
\cline { 3 - 4 } & \multirow{2}{*}{ Discurso } & $\begin{array}{l}\text { Formas particulares de construção textual que } \\
\text { enfatizam conteúdos específicos e se referenciam a } \\
\text { áreas de conhecimento ou campos de prática } \\
\text { (discurso médico, discurso feminista etc.) }\end{array}$ \\
\hline
\end{tabular}

Vimos que os editoriais continham poucas representações diretas, na forma de textos citados. Um exemplo foi uma citação de um importante político questionando a idéia de que o desenvolvimento econômico tem prioridade sobre justiça social e ambiental. As representações indiretas foram mais freqüentes, especialmente aquelas que faziam referência a outros textos publicados na mídia e que continham sugestivas associações com o termo ecologia, tais como: protestos de ativistas ambientais contra modelos que desfilaram com casacos de pele em eventos de moda ("a ecologia do perdão"), o papel do Brasil no cenário do debate ambiental em nível internacional ("a ecologia da liderança"), a ameaça que o aquecimento global representa para algumas espécies ("a ecologia do sapo"), relações entre desenvolvimento econômico e distribuição de renda ("a ecologia do copo"), abordagens humanísticas para a questão da produção industrial ("a ecologia do coração”), políticas do então recentemente eleito Presidente da República ("a ecologia da esperança") e relações humanas no mundo corporativo (“a ecologia do sucesso'). É interessante notar que apenas uma delas, mesmo assim de forma tangencial, fez referência à etimologia da palavra ecologia, em uma menção de que foi Ernest Haeckel que a propôs originalmente em 1866. Outra representação indireta de uma idéia 
relacionada ao discurso científico foi curiosamente ilustrada por um poema de Adélia Prado que fala sobre os seres humanos como apenas mais um grupo de organismos que tomam parte num fluxo de matéria e energia.

Da mesma forma, gêneros científicos não se fizeram presentes nos textos analisados nem houve referências a fontes tais como livros, relatórios, entrevistas com cientistas etc. Um dos poucos textos que continham elementos, ainda que fracamente, ligados ao discurso científico correspondia ao uso de metáforas para descrever o aquecimento global ("a Terra está fervendo", Setembro 2002) e comparações entre visões atribuídas ao Presidente Lula e a um escritor de textos de divulgação científica sobre as relações entre desenvolvimento sustentável, valores humanos e crescimento econômico, realizadas por meio de paráfrases.

Ao propor o desenvolvimento sustentável, onde o social, o meio ambiente e o humanismo vêm juntos, antes, ou como causa maior, do crescimento econômico, Lula nos faz lembrar de uma obra famosa que encantou e fez sonhar várias gerações: O Ponto de Mutação, de Fritjof Capra (Janeiro, 2003).

O conceito de ecologia presente nos textos analisados não dialogou com suas bases científicas. Não encontramos neles alusões a tópicos presentes no debate científico contemporâneo, a argumentos baseados em evidências, a dados de pesquisa ou a vocabulário específico. Em uma das poucas referências a conceitos relacionados ao discurso científico, a saúde foi tratada de forma reducionista, como sinônimo de bem-estar, e a preservação de recursos naturais, como a água, foi mencionada como melhoria na qualidade de vida e requisito para uma melhor relação entre homem e natureza. Com isso, a revista deixa de qualificar a discussão acerca das questões ambientais, uma vez que não recorre aos profissionais que produzem conhecimento cientifico acerca dessas questões. Também não foram identificadas menções a conhecimentos tradicionais ou populares acerca das questões ambientais.

Se, por um lado, foi difícil encontrar relações entre o texto da revista e elementos do discurso científico, por outro lado, houve muitas situações em que detectamos relações entre o texto e elementos do discurso político. Tipicamente, encontramos o uso de jargões e a 
estratégia de criação, no universo simbólico do texto, de um interlocutor que representava um opositor das idéias apresentadas. Por exemplo, muito freqüentemente, esses interlocutores eram questionados acerca das razões pelas quais políticos ou empreendedores resistem a uma visão de ecologia como ambientalmente correta, socialmente justa e vinculada a práticas economicamente sustentáveis ou, em outras palavras, a uma "revolução silenciosa" (Junho 2002). No entanto, apesar de enfatizar o caráter "revolucionário" do debate acerca das questões ambientais, o texto dos editoriais acaba por neutralizar esse aspecto ao trabalhar com um conceito de desenvolvimento sustentável muito próximo àquele adotado por setores empresariais. Ao fazê-lo, acaba por justificar a manutenção de um modelo desenvolvimentista atento aos custos ambientais.

Encontramos também interdiscursos que remetiam ao discurso religioso, freqüentemente caracterizado por dicotomias, tais como bem e mal ou virtude e pecado, bem como por assimetrias entre o escritor/locutor (que traz a palavra de Deus) e o leitor/ouvinte (que é chamado à reflexão). Os exemplos por nós observados incluíram a oposição entre "egoísmo" e "visões ecológicas" (Abril, 2002), referências a um "Jesus ecológico" que diz que a natureza foi criação de Deus e que os humanos são meros atores coadjuvantes no cenário cósmico (Outubro, 2002) e afirmativas de que é impossível negar ou contestar as visões de um dos maiores líderes espirituais do mundo:

A ecologia, na verdade, é o outro nome do amor planetário. Apenas a versão moderna, científica e lógica do que todos os espíritos guias da humanidade já mostraram, como Buda, Cristo, Giordano Bruno, Einstein, Gandhi, Martin Luther King e é impossível negá-los. (Junho, 2002).

Esta análise nos chama a atenção para o fato de que alguns textos da mídia podem estar construindo sentidos sobre meio ambiente nos quais há um "apagamento" da vOz da ciência e a instauração de um estilo que elimina características importantes do gênero científico e que dicotomiza conhecimento e valores. Se, por um lado, o texto revela as complexas interfaces das questões ambientais com temas sociais contemporâneos, por outro lado, eles não caracterizam a ciência como uma prática social nem 
discriminam entre suas bases de inteligibilidade e os argumentos associados a outros discursos, tais como o científico, o religioso, o político etc. Isso é de suma importância, pois textos da mídia acabam por dar os contornos do debate sobre meio ambiente na sociedade e influenciar visões de seus leitores.

O quadro teórico da análise crítica do discurso instrumentaliza o leitor a associar práticas de produção de texto com práticas sociais e discursivas, permitindo assim que leiamos a sociedade através dos textos que ela produz e faz circular. Considerando-se a freqüente apropriação que é feita de textos midiáticos para fins didáticos e pedagógicos, é preciso levar em consideração as condições de produção desses textos e principalmente situá-los dentro dos universos discursivos aos quais eles pertencem. Uma apropriação direta desses textos levaria a uma incorporação do discurso da revista como natural e não como o resultado de uma construção discursiva.

Análises críticas permitiriam, assim, questionar visões hegemônicas e problematizar as mudanças sociais no plano discursivo. Historicizar e desconstruir esses textos pode contribuir para a discussão de dimensões problemáticas do debate das questões ambientais na sociedade. Por exemplo, a constatação de que o discurso sobre meio ambiente se constitui mais intensamente a partir de interdiscursos com os discursos político, religioso e econômico e não com o discurso científico sobre os outros discursos sugere que alguns discursos sobre meio ambiente presentes na mídia contribuem para a manutenção da hegemonia de determinadas dimensões frente às questões ambientais.

\section{Considerações finais}

Neste trabalho, procuramos mostrar que existem bases teóricas e epistemológicas sobre as quais se pode construir uma frutífera interação dos campos de pesquisa da Educação em Ciências e da Educação Ambiental. Em particular, com base em estudos que relacionam linguagem e Educação em Ciências, argumentamos que abordagens fundamentadas em perspectivas críticas para a educação e para o estudo do discurso podem trazer importantes reflexões acerca da natureza do campo, da formação de educadores ambientais e das interfaces do discurso ambiental com outros 
discursos na sociedade. Nesse sentido, sobressaem-se questões relacionadas ao debate provocado pelo confronto de perspectivas modernas e pósmodernas no campo da Educação, entre elas, as relações entre campos de conhecimento, a construção de identidades e o papel do discurso.

Além disso, consideramos que as relações entre a Educação em Ciências e a Educação Ambiental é uma questão que extrapola as considerações acerca da pesquisa nos dois campos e que está aberta ao debate. Essa dimensão não diz respeito apenas à prática de educação ambiental em salas de aula, mas, sobretudo, a como são trabalhadas as orientações sobre educação ambiental e meio ambiente que chegam na escola por meio de discursos oficiais ou por meio da mídia e os conteúdos de Educação Ambiental e meio ambiente em cursos de formação. Inerente a essa discussão, é relevante o papel da formação do educador ambiental e é importante considerar o que está norteando essa formação e como ela está sendo problematizada nos campos da Educação Ambiental e da Educação em Ciências.

\section{Referências}

ABREU, Teo Bueno de. Consideracõoes Acerca da Heterogeneidade do Discurso sobre Meio Ambiente em Textos da Mídia Impressa. 2007. Dissertação (Mestrado em Tecnologia Educacional nas Ciências da Saúde) - Núcleo de Tecnologia Educacional para a Saúde, Universidade Federal do Rio de Janeiro, Rio de Janeiro, 2007.

BARROS, Susana de Souza. Reflexões sobre 30 anos da pesquisa em ensino de Física. In: ENCONTRO DE PESQUISA EM ENSINO DE FÍSICA, 8, 2002, Águas de Lindóia. Atas... Águas de Lindóia: SBF, 2002. p. 1-16.

CARVALHO, Isabel. Invenção e auto-invenção na construção psicossocial da identidade: a experiência constitutiva do Educador Ambiental. In: GUIMARÃES, Mauro (Org.). Caminhos da Educação Ambiental da forma a ação. Campinas, SP: Papirus, 2006. p. 31-50.

CARVALHO, Luiz Marcelo. O discurso ambientalista e a educação ambiental: relações com o ensino das ciências da naturez̧a. In: ENCONTRO NACIONAL DE PESQUISA EM EDUCAÇÃO DE CIÊNCIAS, 6., 2007, Florianópolis. Atas... Florianópolis: ABRAPEC, , 2007. p. 1-15.

DELIZOICOV, Demetrio. Pesquisa em Ensino de Ciências como Ciências Humanas Aplicadas. Caderno Brasileiro de Ensino de Física, Florianópolis, v. 21, n. 2, p. 145-175, 2004.

FAIRCLOUGH, Norman. Discurso e mudança social. Trad. de I. Magalhães. Brasília: Editora da UnB, 2001. 
Semiotic aspects of social transformation and change. In: ROGERS, Rebecca (Ed.). An introduction to critical discourse analysis in education. Mahwah, NJ: Lawrence Erlbaum Associates, 2004. p. 225-236.

FISCHER, Rosa Maria Bueno. Foucault e a análise do discurso em educação. Cadernos de Pesquisa, São Paulo, v. 114, p. 197-223, 2001.

FREIRE, Paulo. Pedagogia do Oprimido. 17. ed. Rio de Janeiro: Paz e Terra, 1987.

GIROUX, Henry. Teoria Crítica e Resistência em Educação: para além das teorias de reprodução. Trad. de A. M. B. Biaggio. Rio de Janeiro: Vozes, 1986.

GOUGH, Anette. Mutualism: a different agenda for environmental and science education. International Journal of Science Education, London, v. 24, n. 11, p. 1201-1215, 2002.

LEFF, Enrique. Epistemologia Ambiental. São Paulo: Cortez, 2002.

LOUREIRO, Carlos Frederico B. Trajetória e fundamentos da educação ambiental. São Paulo: Cortez, 2004.

MARTINS, Isabel. Contributions from critical perspectives on language and literacy to the conceptualization of scientific literacy. In: LINDER, Cedric; ÖSTMAN, Leif; WICKMAN, Per-Olof (Ed.). Promoting scientific literacy: science education research in transaction proceedings of the Linnaeus Tercentenary Symposium. Uppsala, Sweden: 2007. p. 56-63.

OLINISKY, Maíra Jansen. A constituição identitária do campo da Educação Ambiental: uma análise textual da produção de sentidos de licenciandos em Ciências Biológicas. 2006. Dissertação (Mestrado em Tecnologia Educacional nas Ciências da Saúde) - Núcleo de Tecnologia Educacional para a Saúde, Universidade Federal do Rio de Janeiro, Rio de Janeiro, 2006.

KAWASAKI, Clarice Sumi; MATOS, Maurício dos Santos; MOTOKANE, Marcelo Tadeu. O perfil do pesquisador em educação ambiental: elementos para um estudo sobre a constituição de um campo de pesquisa em Educação Ambiental. Pesquisa em Educação Ambiental, São Carlos, v. 1, n. 1, p. 111-140, 2006.

ROBERTS, Douglas. Scientific literacy/Science literacy. In: ABELL, Sandra; LEDERMAN, Norman (Eds.). Handbook of research on science education. Mahwah, NJ: Lawrence Erlbaum Associates, 2007. p. 729-780.

SANTOS, Laísa Maria Freire dos; MARTINS, Isabel. Mapeamento do campo a partir de publicações em periódicos das áreas de educação ambiental, educação em ciências e educação no período de 1999 a 2006. In: ENCONTRO NACIONAL DE PESQUISA EM EDUCAÇÃO DE CIÊNCIAS, 6., 2007, Florianópolis. Atas... Florianópolis: ABRAPEC, 2007 p. $1-11$.

VASCONCELLOS, Maria das Mercês Navarro et al. A perspectiva crítica aproximando os campos da educação ambiental e da educação em ciências. In: ENCONTRO NACIONAL DE PESQUISA EM EDUCAÇÃO DE CIÊNCIAS, 4., 2003, Bauru. Atas... Bauru: ABRAPEC, 2003. p. 1-12.

Artigo recebido em 30/03/2008 - Aprovado em 13/06/2008 